\title{
Spatial distribution of triatomines (Reduviidae: Triatominae) in urban areas of the city of Salvador, Bahia, Brazil
}

\author{
Karine de Souza O. Santana ${ }^{1}$, Maria Emília Bavia ${ }^{1}$, Artur Dias Lima², Isabel Cristina \\ S. Guimarães ${ }^{3}$, Ênio Silva Soares ${ }^{4}$, Marta Mariana Nascimento Silva ${ }^{1}$, Jorge Mendonça ${ }^{4}$, \\ Moara de Santana Martin ${ }^{1}$
}

${ }^{1}$ Federal University of Bahia, School of Veterinary Medicine, Preventive Medicine VeterFamily and Friends Pacificainary Department, Laboratory of Monitoring Disease by GIS, Salvador, Brazil; ${ }^{2}$ State University of Bahia, Life and Science Department, Salvador, Brazil; ${ }^{3}$ Municipal Health Secretariat, Center for Zoonosis Control, Salvador, Brazil; ${ }^{4}$ State Health Secretariat, Salvador, Brazil

\begin{abstract}
Environmental changes have a strong influence on the emergence and/or reemergence of infectious diseases. The city of Salvador, Brazil -currently the focus of a housing boom linked to massive deforestation- is an example in point as the destruction of the remaining areas of the Atlantic Forest around the city has led to an increased risk for Chagas disease. Human domiciles have been invaded by the triatomine vectors of Trypansoma cruzi, the flagellate protozoan causing Chagas disease, a problem of particular concern in urban/suburban areas of the city such as the Patamares sector in the north-east, where numbers of both the vector and human cases of the disease have increased lately. To control and prevent further deterioration of the situation, the control programme for Chagas disease, developed by the Bahia Center for Zoonosis Control, has divided the area into a grid of designated surveillance units (ZIs) that are subjected to vector examination. In six out of 98 of these ZIs, 988 triatomes were collected and georeferenced during the 3-year period between 2006 and 2009. The hottest months, that are also generally the driest, showed the highest numbers of triatomines with Triatoma tibiamaculata being the predominant species $(98.3 \%)$ with Panstrongylus geniculatus present only occasionally $(0.6 \%)$. Fifty-four percent of all triatomines captured were found inside the homes, and $48.6 \%$ out of 479 individuals in the affected ZIs selected for analysis tested positive for T. cruzi infection. The study presented here is a pioneering initiative to map the spatial distribution of triatomines based on geographical information systems with the additional aim of contributing to an expanded knowledge-base about $T$. cruzi and its vectors in urban areas and raise public health awareness of the risks involved.
\end{abstract}

Keywords: Trypansoma cruzi, Chagas disease, Triatoma, deforestation, geographical information system, Brazil.

\section{Introduction}

Disordered growth of urban centers enables the spread of disease and emergence of new infections, previously restricted to rural areas (Guimarães and Tavares-Neto, 2006). With regard to infectious diseases in Brazil, Chagas is fourth in causing social and public health impact (Dias, 2001). A national survey, designed to estimate the distribution of human seroprevalence for Trypansoma cruzi and the spread of its triatomine vector, was performed between 1975 and 1980. The results revealed that the northeast part of Brazil is the second most important triatomine-infested

Corresponding author:

Karine de Souza O. Santana

Federal University of Bahia, School of Veterinary Medicine, Preventive Medicine VeterFamily and Friends Pacificainary Department, Laboratory of Monitoring Disease by GIS Salvador, Brazil

Tel. + 55328 36745; Fax + 5532836730

E-mail: kasousan@yahoo.com.br region in Brazil, and that the State of Bahia has the largest variety of triatomine species, mainly belonging to the genera of Triatoma and Panstrongylus (Dias et al., 2000). Presently, 97 of the 417 cities in the country are considered high-risk areas for Chagas (SESAB, 2006). Samples of T. cruzi-infected triatomines have been found in Salvador, the State capital (Dias-Lima and Sherlock, 2000). The intense real-estate expansion, now underway in Salvador, includes clearing of the reminiscent areas of rainforest. These developments are not always preceded by studies of their potential for environmental impact and can, as in this case, develop into a public health challenge. The erosion of triatomine habitats in the woods, now used for construction of homes, has forced the bugs into human domiciles in search for food and shelter (Dias, 2001; Ribeiro, 2006). Housing has thus become an aspect of vector habitat preferences, important enough that even wild species show signs of adapting to artificial domestic ecotypes. For example, even if the Pan American Health Organization (PAHO) certified the 
interruption of Chagas transmission by Triatoma infestans in Brazil already in 2006 (http://portal.saude. gov.br/portal/arquivos/pdf/notatecnica_chagas0806. pdf), wild triatomine species continue to infest buildings and surrounding areas (Caranha et al., 2006).

Surveys carried out in other Brazilian states have shown different vector species inside and outside people's homes. Presence of triatomines, with a T. cruzi infection rate of $14.7 \%$, was found in 51,570 houses in 201 cities in the State of Goias (Oliveira and Silva, 2007). Here, the most common species was T. sordida, followed by P. megistus, and peri-domestic infection was significantly larger than intra-domestic infection. Carvalho et al. (2003) reported a T. cruzi infection of $26 \%$ in the State of São Paulo. The authors also noted a predominance of adult triatomines inside houses, with P. megistus and T. tibiamaculata being the most frequent species. In the State of Espírito Santo, Sessa et al. (2002) reported a large geographical distribution of T. vitticeps with a $64.7 \%$ rate of natural infection by flagellates morphologically similar to T. cruzi. Other species such as $P$. megistus, T. tibiamaculata and P. geniculatus, were also found but with no evidence of them inside the domiciles.

The Bahia Center for Zoonosis Control (CZC) and Fundação Oswaldo Cruz (FIOCRUZ) actively pursue research and control of Chagas disease. The CZC is investing in entomological surveillance by collecting data for its control activities. The Chagas problem has been dormant for many years, but the uncontrolled deforestation under way has brought changes to the biome of Salvador leading to a strongly increased risk of exposure of the population for the vectors, and thus also for T. cruzi infection. The Secretary of Health, favouring the implementation of health education as part of the entomological survey, supports the need for an up-to-date estimate of the geographic triatomine distribution in the municipality of Salvador. In addition, the results of serological investigations of T. cruzi in the residents in whose houses infected triatomines had been found, has boosted the case for T. cruzi surveillance.

Considering the lack of information regarding the fine-scale distribution of Chagas disease, it was felt important to map and evaluate the occurrence of triatomines as well as reinvestigate the spatial distribution of Chagas disease. A further need was to raise general knowledge of the vector, its interaction with the urban environment and impact on public health. The work described here is based on the epidemiological surveillance, performed by CZC and FIOCRUZ to assess the risk of Chagas disease.

\section{Materials and methods}

The study area is located around latitude $13^{\circ} 00^{\prime} 00^{\prime \prime}$, South and longitude $38^{\circ} 30^{\prime} 00^{\prime \prime}$, West, coinciding with the boundaries of Salvador, Bahia. The city has a mean altitude of $50 \mathrm{~m}$ above the mean sea level (MSL) and a hilly, undulating topography. The average annual temperature is $25.3{ }^{\circ} \mathrm{C}$ and the weather is humid with a rainy period between April and June (mean annual rainfall $=1,902 \mathrm{~mm}$ ), the type of climate favouring evergreen rainforests. The population in this area is estimated at 2.6 millions individuals with an urbanization rate of $99.1 \%$ and a demographic density of 8,085 inhabitants $/ \mathrm{km}^{2}$ (Instituto Brasileiro de Geografia e Estatística - IBGE - Censo 2000, http://www.ibge.gov.br/censo/).

Entomological surveillance has been organised by the Chagas Disease Programme (CPCD), which encourages the general population to collect and send in the typical triatomine bugs to one of 21 designated Offices for Information on Triatomines (PITs). All triatomines captured in the period 2006-2009 were sent to the entomology laboratory at FIOCRUZ. The insects were identified based on external morphology and analysed according to species, developmental stage and sex. They were also checked for infection by trypanosome flagellates and classified and registered according to the location where they were found, i.e. inside the domicile, in the peri-domicile areas (garden, swimming pool, garage) or in extra-domicile areas (outside the home and its immediate vicinity). Areas searched were selected according to the potential of finding anything such as areas where triatomines had been captured before, i.e. remaining rainforest, or deforested land with records of triatomine presence. In addition, following the protocol of the Ministry of Health $(\mathrm{MoH})$ in Brazil for homes found to be infected by triatomines, registration was accompanied by technical surveillance and serological evaluation of human T. cruzi infection.

A map of Salvador, at a scale of 1:2,000 with the mesh axis of the streets of the metropolitan area, produced by the Company of Urban Development of the State of Bahia, was used to prepare the cartographic base. The mesh surveillance information zones (ZI) used in this study represents the division of the city into areas adopted by the Brazilian Institute of Geography and Statistics. A geographical information system (GIS) was structured on the digitalised, cartographically referenced database. The addresses at which the presence of triatomines was detected were plotted on the digitised map. This information was 
linked to the epidemiological, georeferenced database using ArcView, version 9.3 (ESRI, Redlands, CA, USA). The data were entered into an Excel 2007 spreadsheet and the evaluation performed based on descriptive, statistical analysis using Stata, version 10.0 (College Station, TX, USA).

\section{Results}

Over the 3-year study period, 2007 had the highest triatomine count of specimens. January scored the highest number registered in any month (167), followed by December and October. It should be noted that November-April is the hottest period, while September-March has the least rain.

More than half of all the potential insect vectors captured $(51.5 \%)$ were not in a condition that they could be examined. Of those that could be investigated, 988 were registered as belonging either to the species of T. tibiamaculata $(98.3 \%)$ or to P. geniculatus $(0.6 \%)$. The geographical distribution of the triatomines captured showed a strong concentration (971 specimens) in the Patamares region (ZI-46). Only small numbers were reported from other areas (Table 1). At the domicile level, $16.6 \%$ of the T. tibiamacula$t a$ were collected inside the houses, $39.9 \%$ in the peridomicile areas and $43.5 \%$ outside. Half of the $P$. geniculatus samples were collected inside the houses, $33.3 \%$ in the peri-domicile areas and $16.7 \%$ outside. Indeed, $56 \%$ of all the triatomines were found in the peri-domicile area with T. cruzi present in 54\% of all triatomines collected inside the residences.

Of all the triatomines collected, $35.0 \%$ were males, $28.6 \%$ females and $36.4 \%$ nymphs. With regard to the place of collection, $43.3 \%$ of the 988 specimens were collected outside the residences, $39.9 \%$ in the peri-domicile areas and $16.8 \%$ inside the residences (Figs. 1-3). Despite the fact that domicile inside areas are not generally favoured by the triatomines, samples were captured in bathrooms, bedrooms, living rooms and in prams parked inside.

Interestingly, as many as 233 out of the 479 specimens that were in good enough condition to be tested, were found to be infected with T. cruzi. The prevalence index of $T$. cruzi infected bugs was calculated for each ZI, with the exception of ZI-61 and ZI-63 as the density of triatomines in these areas was very low. The highest prevalence index was registered in ZI-46 (23.5\%), followed by ZI-54 with $20 \%$. T. cruzi infection was not recorded in ZI-42 and ZI-69 (Table 1, Figs. 1-4). High numbers of T. cruzi infection of the specimens were registered in December, March and July.

\section{Discussion}

The idea to ask the general population to capture bugs and send them in for examination, proved useful in that many specimens could be gathered. On the other hand, due to lack of knowledge regarding storage of the collected insects, the number that could be examined was reduced to less than half. To improve the special care required for the collection of the bugs, the CZC has created an informative and educational programme involving the population in each PIT and the regional high schools.

Clearly, the number of triatomines in the city is increasing and it is plausible that this is linked to the higher number of Chagas cases in Salvador as suggested by Dias-Lima and Sherlock (2000). Due to the potential role of secondary vectors, the question of species is important. As pointed out by Marçal and Macedo (2004), attention should be drawn to the possible role of P. geniculatus, T. tibiamaculata, Rhodnius prolixus, $R$. domesticus and T. vitticeps, once these species start moving inside human premises. The peridomicile, i.e. garden, backyard and garage, can be considered as an area of transition between the inside and the outside of the house. The fact that more than half of the triatomines were found here, suggests the possible adaptation of triatomine to an artificial envi-

Table 1. Location and numbers of triatomines captured in the period 2006-2009 in Salvador, Bahia.

\begin{tabular}{lcc}
\hline Surveillance unit (ZI) & Number & Prevalence $(\%)$ \\
\hline 46-Patamares & 971 & $23.5 \%$ \\
42-Fazenda Grande & 3 & N. d. \\
54-Trobogy, Jardim Nova Esperança Vale dos Lagos & 10 & $20 \%$ \\
61-Mussurunga & 2 & N. d. \\
63-Piraja & 1 & N. d. \\
69-Cajazeiras/Aguas Claras & 1 & N. d. \\
\hline Total & 988 & N. a. \\
\hline
\end{tabular}

N. a., not applicable; N. d., not determined 


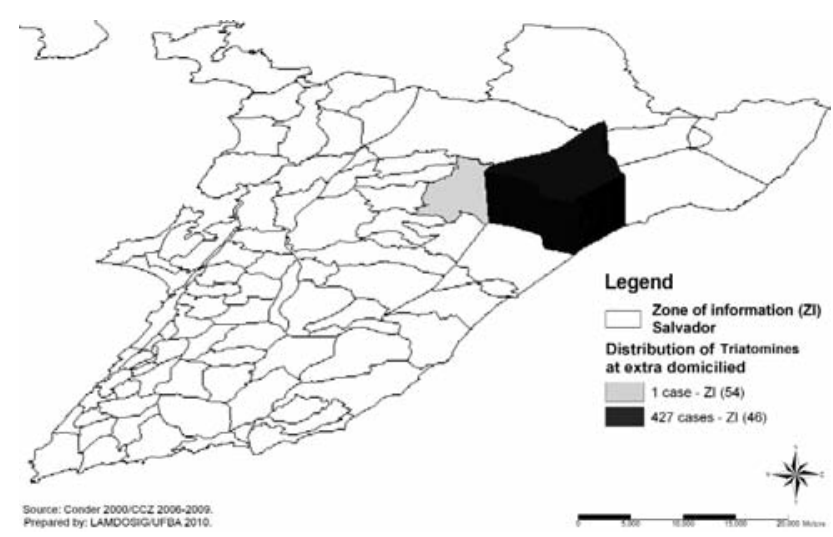

Fig. 1. Spatial distribution of extra domicile findings of triatomines in Salvador, Bahia, Brazil (2006 -2009).

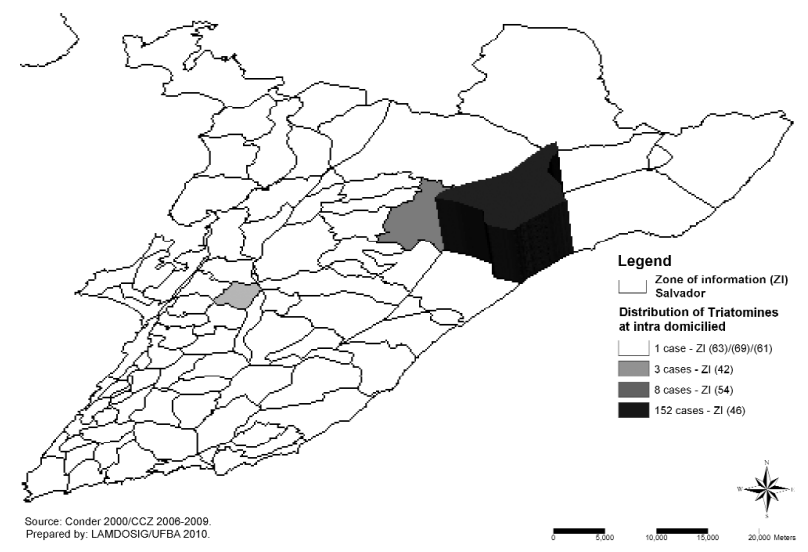

Fig. 3. Spatial distribution of intra-domicile findings of triatomines in Salvador, Bahia, Brazil (2006-2009).

ronment. The occurrence of female triatomines may influence the risk of vector colonisation as well as the high number of nymph stages captured around domiciles. Although not found in the intra-domicile area, the regular presence of the nymph stage indicates the possibility of a beginning domiciliation of the vector.

A progressive change in the Salvador's biome has been registered (Ribeiro, 2006). The uncontrolled deforestation coupled with strong real-estate expansion is nurturing the human exposure to triatomines in an urban environment. For example, we observed that specific areas in Salvador, such as Patamares (ZI 46), not only have the highest triatomine frequencies but also feature a wide distribution of palm trees. This correlation cannot be statistically assured at this stage, but the observation agrees with that by Gurgel-Goncalves et al. (2004), who consider palm groves an indicator of increased ecological risk for Chagas disease. However, what is already obvious is that the destruction of the ecosystems promotes the reduction or extinction of natural blood sources for wild triatomines, which favours their invasion of the households. With about

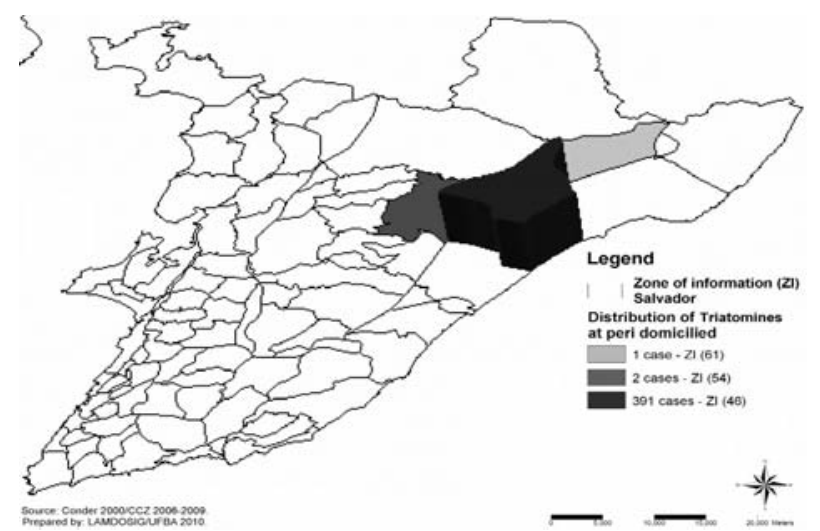

Fig. 2. Spatial distribution of peri-domicile findings of triatomines in Salvador, Bahia, Brazil (2006-2009).

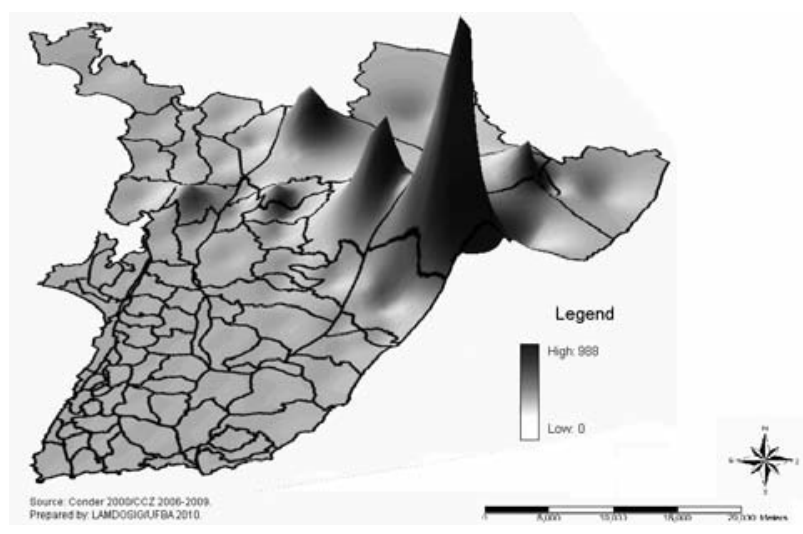

Fig. 4. Triatomine distribution in the surveillance units (ZIs) in Salvador, Bahia, Brazil (2006-2009).

half of the vectors carrying T. cruzi, and large numbers of people living in and around such areas, the risk for a Chagas epidemic is gradually increasing (Ribeiro, 2006). The contact between vectors and human beings is further encouraged by the approach to human domiciles by the natural triatomine food sources, such as wild marsupials, rodents and birds. Due to changes in their environment, these animals also adapt themselves to artificial ecotypes.

\section{Conclusions}

The study shows the extent of the consequences of disorderly occupation of space in relation to public health, and indicates the need to strengthen the dialogue between private construction companies and public authorities.

The entomological surveys carried out provide an estimate of the geographic triatomine distribution in the municipality of Salvador, Bahia, drawing attention to the fact that the increased numbers of triatomines presents a risk that must be confronted. In 
addition, the serological investigation for $T$. cruzi infection in people living in homes with a record of infected triatomines boosts the need for continued and enlarged surveillance with respect to $T$. cruzi infection. The common presence of infected triatomes in urban areas, underlines the increasing risk for a Chagas epidemic.

The dearth of literature on the geographic distribution of triatomines reinforces the necessity of mapping the occurrence of these insects and favours improving the general knowledge about their behaviour. It is also important to identify cluster areas and develop guiding strategies for surveillance and control. The absence of up-to-date studies strengthens the case for stronger action with regard to the environmental impact of new housing projects and underlines the need for eco-epidemiological surveys with respect to underlying risk factors. However, the implementation of the surveillance posts (the PITs) has facilitated control activities and contributed to the development of a health education component.

\section{References}

Caranha L, Lorosa ES, Rocha DS, Juberg J, Galvão C, 2006. Estudo das fontes alimentares de Panstrongylus lutzi (Neiva \& Pinto, 1923) (Hemiptera: Reduviidae: Triatominae) no Estado do Ceará. Rev Soc Bras Med Trop 39, 347-351.

Carvalho ME, da Silva RA, Barata JM, Domingos MF, Ciaravolo RM, Zacharias F, 2003. Chagas' disease in the southern coastal region of Brazil. Rev Sau Pub 37, 49-58.

Dias JCP, 2001. Doença de chagas, ambiente, participação e Estado. Cad Sau Pub 17, 165-169.

Dias JCP, Machado EMM, Fernandes A, Vinhaes MC, 2000.
Esboço geral e perspectivas da doença de Chagas no Nordeste do Brasil. Cad Sau Pub 16, 13-34.

Dias-Lima A, Sherlock IA, 2000. Sylvatic vectors invading houses and the risk of emergence of cases of Chagas disease in Salvador, State of Bahia, Northeast Brazil. Mem Inst Oswaldo Cruz 95, 611-613.

Gurgel-Gonçalves R, Duarte MA, Ramalho ED, Palma AR, Romaña CA, Cuba-Cuba CA, 2004. Spatial distribution of Triatominae populations (Hemiptera: Reduviidae) in Mauritia flexuosa palm trees in Federal District of Brazil. Rev Soc Bras Med Trop 37, 241-247.

Guimarães ICS, Tavares-Neto J, 2006. Transmissão urbana de esquistossomose em criança em um bairro de Salvador, BA. Rev Soc Bras Med Trop 39, 451-455.

Marçal Jr O, Macêdo HS, 2004. Distribuição de vetores da doença de chagas em nível domiciliar: um estudo na zona rural de Uberlândia (MG). Cam Geogr 3, 50-66.

Oliveira AWS, Silva IG, 2007. Distribuição geográfica e indicadores entomológicos de triatomíneos sinantrópicos capturados no Estado de Goiás. Rev Soc Bras Med Trop 40, 204-208.

Ribeiro Jr G, 2006. Ocorrência de Triatomíneos (Hemiptera: Reduviidae) em Residências próximas a remanescentes florestais de Salvador e caracterização das Cepas de Trypanosoma cruzi isoladas. Monografia, Universidade Católica de Salvador, 54 pp. SESAB - Secretaria de Saúde do Estado da Bahia, 2006. Superintendência de Vigilância em Saúde. Diretoria de Vigilância Epidemiológica. Informe da Situação do Controle da Doença de Chagas, com especial referência aos avanços logrados na interrupção da transmissão vetorial por Triatoma infestans, $63 \mathrm{pp}$.

Sessa PA, Pimentel RR, Ferreira A, Falqueto LA, 2002. Soroprevalência da doença de Chagas em crianças em idade escolar do Estado do Espírito Santo, Brasil, em 1999-2000. Cad Sau Pub 18, 1765-1769. 